\title{
Current Status of Black-Necked Crane Grus Nigricollis in Southern Xinjiang China: Conservation Implications
}

Mardan Aghabey Turghan ( $\nabla$ mardan@ms.xjb.ac.cn )

Xinjiang Institute of Ecology and Geography https://orcid.org/0000-0002-9183-198X

Paul Jason Buzzard

China Exploration and Research Society,Hong Kong China

Roller Maming

Xinjiang Institute of Ecology and Geography

\section{Research Article}

Keywords: Black-necked Crane, Altun Mountain, Kunlun Mountain, Lop Nur Basin, Conservation

Posted Date: February 11th, 2021

DOl: https://doi.org/10.21203/rs.3.rs-180720/v1

License: (c) (i) This work is licensed under a Creative Commons Attribution 4.0 International License. Read Full License 


\section{Abstract}

In this paper, we update the status of Black-necked cranes (Grus nigricollis) in Xinjiang Uyghur Autonomous Region, China where it has hardly been recorded. We report on research in Southern Xinjiang $₫$ mainly in Altun (Arjin in Chinese) and Kunlun Mountain ranges and their adjacent areas, including part of Pamir Plateau and the southern edge of Lop Nur Basin. Black-necked cranes were observed in seven counties, by direct observation in 2010 to 2017, and we deduced that 180-220 individuals of the species inhabited Kunlun and Altun Mountains and the surrounding areas. 137 cranes, the largest population, were recorded in the autumn migration season in the Altun Mountain Nature Reserve in 2013. The most recent record of Black-necked cranes in the Lop Nur Basin ( N 40¹9', E 915', alt. $790 \mathrm{~m}$ ) was observed on May 2010 would be the northernmost distribution location with the lowest

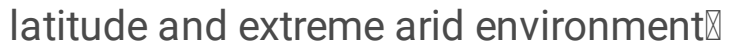

\section{Introduction}

Black-necked cranes Grus nigricollis, a Globally Vulnerable species endemic to Tibetan Plateau, was the last of the world's cranes to be discovered by the scientific community (BirdLife International 2001). Its range covers $28^{\circ}-41^{\circ} \mathrm{N}$ and $78^{\circ}-104^{\circ} \mathrm{E}$, stretching from the Altun and Kunlun mountain ranges east to the Qimantagh and Wumeng Mountains and south to Himalayas (Bishop 1996). It was first recorded by the Russian naturalist, Count Przewalski near Kok Nor Lake in north-eastern Tibet in 1876, and sighted by the Russian naturalist, P. K. Kozlov in Altun Mountains, Xinjiang China on his second expedition to Tibetan Plateau in 1899-1901 (Schaller, 1998; Luo, 2005). Xinjiang, dotted with some of the world's most unique and spectacular wetlands, also holds the distinction of being one of the known breeding grounds of Black-necked cranes in China. According to its migration patterns, Black-necked cranes are divided into western, central and eastern populations (Li and Bishop, 1999), and those that breed in Xinjiang at the northern edge of the Tibetan Plateau belong to the western population. Due to geographical inaccessibility and lack of scientific research across much of its range, the status of Black-necked cranes in Xinjiang remained unknown until it was rediscovered in Altun Mountain Nature Reserve in the 1980s (Chen, 1985; Gao, 1986; Huang et al., 1989; Feng, 1991). There have been few studies of its distribution that estimate its population. In this paper, we summarize the current population distribution of Blacknecked cranes in Xinjiang, China and provide a population estimate based on direct field observations, questionnaire surveys and previously-published studies in order to a provide a scientific baseline to monitor future population trends, as well as to document the major threats to the species conservation.

\section{Materials And Methods}

This study was mainly conducted in the Altun and Kunlun mountain ranges on the edge of the Tibetan Plateau and adjacent areas including parts of the Pamir Plateau and wetlands of the Lop Nur Basin, as these sites have been demonstrated as potential habitats of Black-necked cranes by previous reports (References). The elevation ranges from 3,800-6,900 $\mathrm{m}$ and mountains above 5,500 $\mathrm{m}$ have permanent snow (Butler et al., 1986; Achuff and Petocz 1988; Bleisch et al. 2009). The climate of the area is 
continental, dry and cold with average daily temperatures from -21 to $2.4^{\circ} \mathrm{C}$ in winter and -3.4 to $21^{\circ} \mathrm{C}$ in summer. Precipitation is sparse and frequently falls as snow or sleet even in summer. The Altun Nature Reserve, covering an area of $45,000 \mathrm{~km}^{2}$ and characterized by high elevations, low annual precipitation, low nutrient levels and extremely cold weather in the winter (Butler et al., 1986; Achuff and Petocz 1988; Ablimit, 2004, Ma, 2010; Mardan et al., 2013, Mardan et al,. 2021).

We also surveyed the suspected areas within the Pamir Plateau, Tarim River Basin and Bostan Lake which were reported to presumably have crane distributions (Fig. 1, areas with the question marks) ( Chen, 1985; Gao, 1986; Huang et al., 1989; Feng, 1991; Tian, 1999). These reports assumed that there may be ideal habitats for large populations of the species, and that, there were more than 1000 Blacknecked cranes in Xinjiang. We assume that this population estimate is too large because it is not justified to extrapolate the density of the main distribution regions to the total area, given that approximately $20 \%$ of the total area of Xinjiang is considered to be suitable habitat for Black-necked cranes (Tian, 1999; Ma et al., 2011).

The present study comprises the second nation-wide field survey of wildlife resources of China, which was initiated in 2010 and completed in November 2017. The entire population was counted with direct count method at a total of 25 sampling sites (Fig. 1). Surveys were made in March-April, and OctoberNovember to establish the arrival and departure dates of the species. Data was collected on the number of individuals, nests, number of eggs laid, hatching success and survival of fledglings (Oring and Lank 1982). Nikon binoculars and spotting scopes were used to spot the birds. Locations were taken using a Garmin 12 CX GPS. A digital stop watch, a hand tally counter and a still camera were used to record specific events. Direct or visual count method was used to count the birds. Such a method has been widely used for counting aquatic birds (Eltringham and Atkinson 1961; Roux 1973; Zewarts 1976; Alford and Bolen 1977; Amat 1984; Sridharan 1989). Interviews with local wardens and pastoralists, and officials of the administrative were administered to get information on the distribution and conservation status of the cranes. The severities of the potential threats to the cranes at different sites were estimated based on literature reviews, preliminary interviews and field assessment. We analyzed our survey data using SPSS 15.0 (SPSS 2005).

\section{Results And Discussion}

We observed Black-necked cranes in seven Counties within the the Altun and Kunlun mountain ranges and their adjacent areas viz., Qakilik County (Qimantagh, Altun Mountain Nature Reserve, Lopnur Basin), Qarqan County (Tura Wetland on the upper stream of Qarqan River), Guma County (Karkash River), Hotan County (Aksayqi Lake, Hotan River, Yorunkax River), Karkash County (Yorunkash River), Kaghilik County (Zarapshan River, Yarkant River) and Aktu County (Pamir Peak, Aktu Wetland) (Fig. 1, Table 1).

We estimated that 180-220 Black-necked cranes inhabited Southern Xinjiang viz.,Kunlun and Altun Mnts and the surrunding areas. () Among them, the Altun Mountain Nature Reserve is the most important breeding ground in Xinjiang, followed by the Aksayqi Lake and Yorunkash River Basin in Kunlun 
Mountains, indicating that, populations at Dashanbao and Napahai in Altun and Kunlun Mountains constitute the bulk of Black-necked crane breeding and wintering grounds outside Tibet and Yunnan in China. The most cranes, 137 in total were recorded during the autumn migration season in the reserve in 2003. A lone crane was observed on the wetland of Aqqik walley at the southern edge of Lop Nur Basin ( N 40 $19^{\prime}$, E $91^{\circ} 58$ ) on May 2010, the northernmost distribution location of the species in Xinjiang.. Furthermore, this record has extended the distribution region of this typical Qinghai-Tibetan Plateau species northwards by $2^{\circ}-3^{\circ}$ latitudes. As we expected, there were no cranes recorded in the suspected distribution locations above this latitude, in Tarim River Basin and Bostan Lake. The Cranes were observed in the Pamir Plateau only occasionally. A few individuals remained in the valley till October but they did not make any attempt at nesting, and some of them were not spotted again in subsequent visits (Fig. 1, Table 1). 
Table 1

The distribution and population size of Grus nigricollis in Xinjiang (2010-2017)

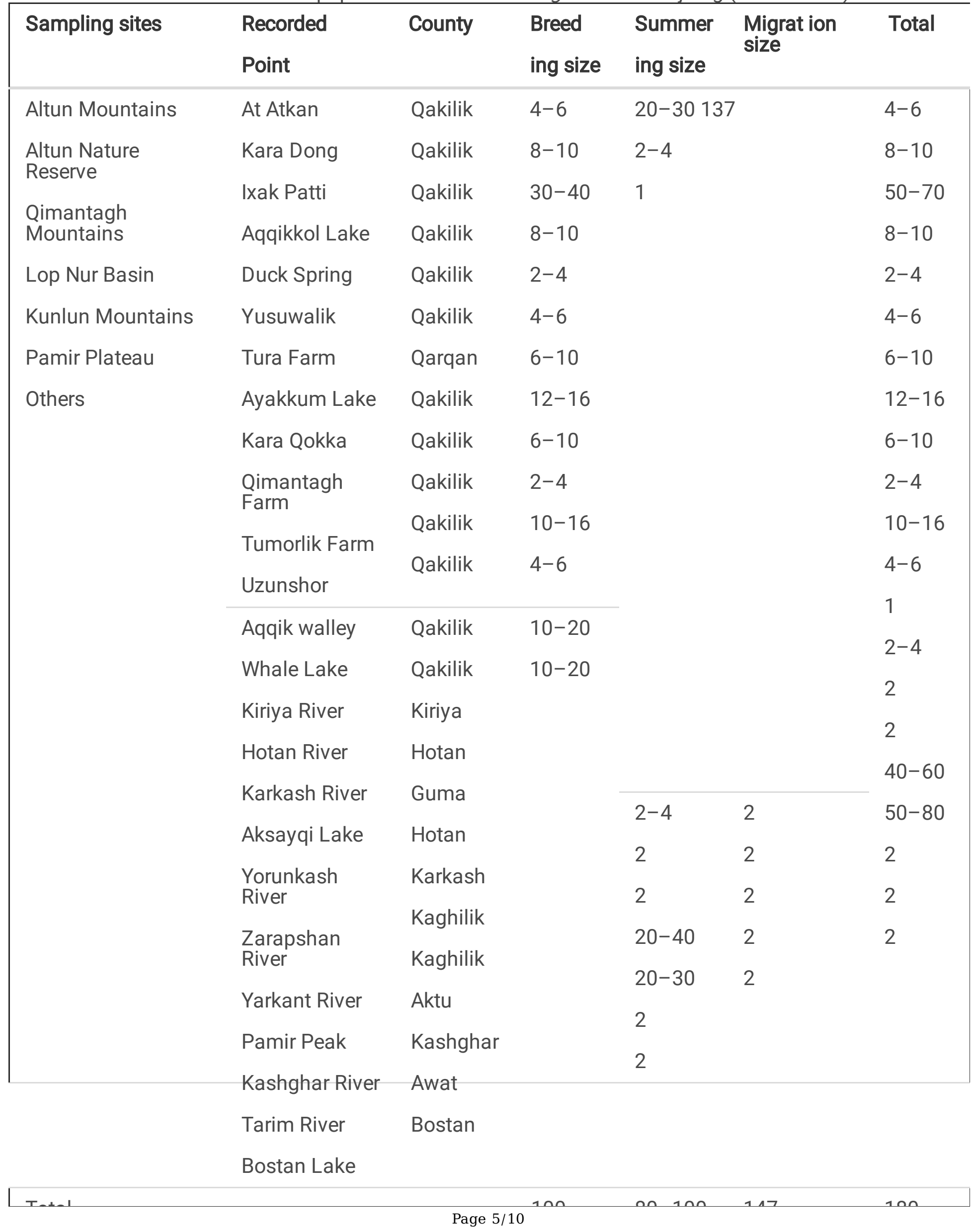




\begin{tabular}{|lllllll}
\hline Sampling sites & Recorded & County & Bered & Summer & $\begin{array}{l}\text { Migrat ion } \\
\text { size }\end{array}$ & Troftal \\
\hline Conservation Implication & Point & & ing size & ing size & \\
\hline
\end{tabular}

Although the current status of Black-necked cranes in Xinjiang, is encouraging, the species is still under threat mainly due to the ever increasing human-wildlife conflict within its distribution from wetland loss and degeneration. Our analysis based on field monitoring, questionnaire surveys and previous research indicates that though the population seems to be increasing, the overall breeding productivity is declining. The increase in the population is due to the easy human access into new breeding sites and populations while the decline in breeding success is due to increased human activities, and secondary impacts, like direct killing by dogs as well as pressure on habitat because of human development. The intensity of the potential threats varied between sites, in which intensified competition with domestic livestock, road infrastructure construction and mining activities pose major threats to populations of overwintering cranes. We recommend that such threats need to be addressed and monitored specifically in future for the better conservation the species. Our study proposes well-protected reserves, enforcement of regulations against illigal hunting, and management and protection of the species' potential habitat. Therefore, in addition to ongoing research, further studies are needed on the use of lakes, rivers and marshes as stopover sites along migratory routes and as pre-wintering sites. Furthermore, changes in the environment of such stopover sites in the early and later stages of the overwintering period should also be addressed. It is also hoped that this research will inspire further in-depth work on this unique species and the ecosystems that support it.

\section{Declarations}

\section{ACKNOWLEDGEMENTS}

This work, financially supported by the National Natural Science Foundation of China (Grant No. 30970340-31272291), comprises the second nation-wide field survey of wildlife resources of China. We also thanks for the financial support by China Nature Conservation Project of Hong Kong Bird Watching Society (Grant No. 2012002). This work has been accomplished thanks to the assistance of all the staff of the Altun National Nature reserve. We also thank Kawsar Aman and Qughlukh Mardan for their attention during our research.

\section{DECLARATION}

\section{Funding :}

1. The research $₫$ a part of the second nation-wide field survey of wildlife resources of China $\$ was financially supported by the National Natural Science Foundation of China (Grant No. 3097034031272291).

2. Financial support was also provided by China Nature Conservation Project of Hong Kong Bird Watching Society (Grant No. 2012002). 
Conflicts of interest/Competing interests:

The authors declare that there are no conflicts of interest regarding the publication of this paper.

\section{Availability of data and material:}

The datasets used and/or analysed during the current study are available from the corresponding author on reasonable request (Corresponding author: Dr. Mardan Aghabey Turghan囚mardan@ms.xjb.ac.cn).

\section{Ethics approval:}

Ethics approval was not required for this study according to legislation of Chinese Wild Animal Protection Law (CWAPL).

\section{Consent to participate:}

Not Applicable

\section{Consent for publication:}

All authors provided written informed consent to publish the data contained within this article.

\section{Code availability:}

We analyzed our survey data using SPSS 15.0 (SPSS 2005).

\section{Authors' contributions:}

All authors whose names appear on the submission made substantial contributions to the conception or design of the work; or the acquisition, analysis, or interpretation of data:

1. Mardan Aghabey Turghan conceived and designed the study and performed the experiments and also contributed significantly to analysis and manuscript preparation.

2. Paul Jason Buzzard made substantial contributions to the conception or design of the work and manuscript preparation and its revision, and was a major contributor in writing the manuscript

3. Roller Maming made substantial contributions to the interpretation of data and helped perform the analysis with constructive discussions.

All authors approved the version to be published, and agree to be accountable for all aspects of the work in ensuring that questions related to the accuracy or integrity of any part of the work are appropriately investigated and resolved.

All authors read and approved the manuscript.

\section{References}


1. ABLIMIT, A., 2004. The National-Level Protected Wildlife in Xinjiang (in Chinese). Xinjiang, China.

2. ACHUFF, P., AND PETOCZ, R., 1988. Preliminary Resource Inventory of the Altun Mountains Nature Reserve, Xinjiang, People's Republic of China: WWF Project 3642 Report, World Wide Fund for Nature, Gland, 78 pp.

3. ALFORDIford, J.R., and E.G. BOLEN., 1977. Influence of winter temperature on Pintail sex ratios in Texas. Southwest Nat. 21 (4) : 554-6.

4. Amat, J. A., 1984. Ecological Segregation Between Red-crested Pochard Netta rufi na and Pochard Athya ferina in a fluctuating environment. Ardea $72: 229-33$

5. Birdlife International (2001). Threatened birds of Asia: The bird life international red data book. Birdlife International, Cambridge.

6. BISHOP, M.A,. 1996. Report on Investigations of Status, Distribution and Winter Habitat Use by Blacknecked Cranes in Southcentral Tibet, 1990-4, ICF, Baraboo.

7. BLEISCH, W. V., P. J. BUZZARD, H. B. ZHANG, D.H. XU, Z.H. LIU, W .D. LI, AND H. M. WONG. 2009. Surveys at a Tibetan antelope Pantholops hodgsonii calving ground adjacent to the Altunshan Nature Reserve, Xinjiang, China: decline and recovery of a population. Oryx 43:191.

8. BUTLER, J., ACHUFF, P. AND JONSTON, J,. 1986. Altun Mountains Nature Reserve, Xinjiang, People's Republic of China. WWF-IUCN, Gland.

9. CHEN, G., 1985. China establishes more nature reserves. Biol Conserv., (in Chinese), 36: 1-5.

10. ELTRINGHAM, S.K., ATIKSON.W., 1961. Recent population changes in British ducks. 12th Ann. Rep. Wildfowl Trust : 430-57.

11. FENG, Z., 1991 On the status and conservation of wildlife resources in the Karakorum-Kunlun mountain region, China. Chinese Journal of Arid Land Research, (in Chinese), 4:65-74.

12. GAO, X., 1987. Bird species in eastern Kunlun and Altun Mountain. Arid Zone Research., (in Chinese), 4: 1-10.

13. HUANG, R., AND GAO, X., 1989. Research on the Feeding Habits of the Bird Species in Altun Mountain and its Neighboring Regions. Sichuan Journal of Zoology, (in Chinese), 1989 8: 34-36.

14. Li, F.S., and BISHOP, M.A.. Ecology and conservation of Black[1]necked cranes Grus nigricollis. In: Adams NJ, Slotow RH (eds) Proc 22 Int Ornithol Congr, Durban. BirdLife South Africa, Johannesburg, pp 2533-2543.

15. LUO, W.H., 2005. History of Westren Botanical and Zoological Studies in China (in Chinese). Shandong Education Press, Shandong, China.

16. MA,M. 2011. A checklist on the Distribution of the Birds in Xinjiang (in Chinese). Science Press, Beijing, pp 39-40.

17. MA, M., HU, B., MEI, Y AND TOMAS, M., 2010. Survey on Bird Species and Analysis on Bird Diversity in the Central Kunlun Mountains in the Early Winter. Arid Zone Research, (in Chinese), 27: 230-235. 
18. MARDAN, T., MA, M., ZHANG, X. AND ZHANG, T., 2013. Current population and conservation status of the Tibetan Wild Ass (Equus kiang) in the Altun Mountain Natural Reserve, China. Pakistan J. Zool., 45: 1249-1255.

19. ORING, L.W., D.W. LANK, 1982.Sexual Selection, Arrival Times, Philopatry and Site Fidelity in the Polyandrous Spotted Sandpiper. Behav. Ecol. Sociobiol. 10 : 185-91.

20. ROUC, F., 1973. Censuses of Anatidae in the Central Delta of the Niger and the Senegal Delta-January 1972. Wildfowl 24 : 63-80.

21. SCHALLER, G., 1998. Wildlife of the Tibetan Steppe. Chicago. The University of Chicago Press.

22. SRIDHARAN, U., 1989. Comparative Ecology of Resident Ducks in Keoladeo National Park, Bharatpur. Ph.D. thesis, University of Bombay, Bombay.

23. TIAN, F,L., 1999. Plateau bird - Black-necked crane. Environ Pro[1]tect Xinjiang, 4:63. (in Chinese).

24. Turghan, M. A. , Ma, M. , Jie, D. 2019. An updated checklist of bird species in the Altun mountain nature reserve, china: conservation implications. Pakistan Journal of Zoology. https://dx.doi.org/10.17582/journal.pjz/20181010091000

25. ZEWARTS, L., 1976). Density Related Process in Feeding Dispersion and Feeding Activity of Teal (Anas crecca). Ardea 64 : 192-209.

\section{Figures}




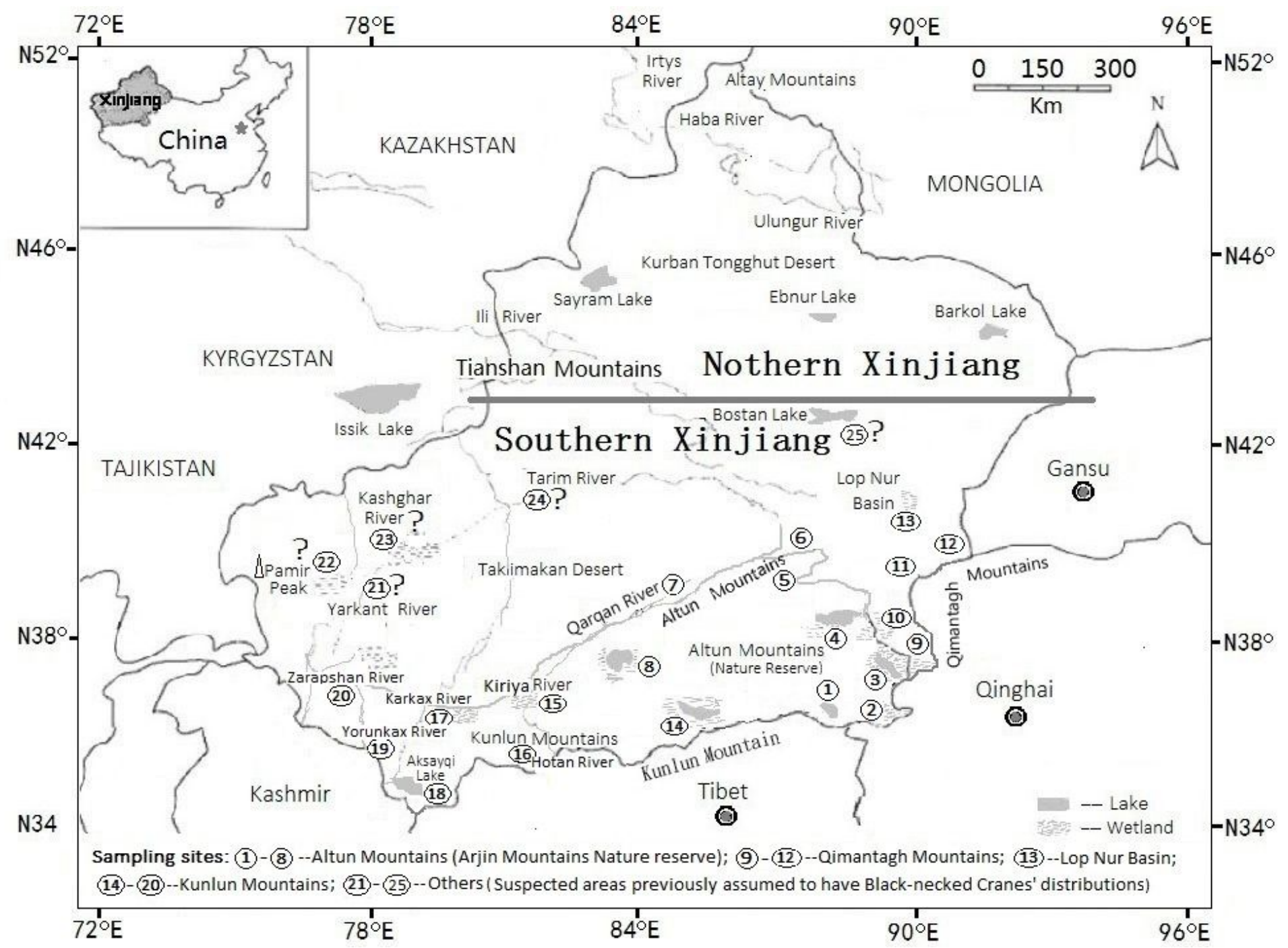

\section{Figure 1}

The geographical map of Xinjiang China, the Kunlun and Altun mountain regions in Southern Xinjaing were considered to be main the distribution locations of Black-necked-cranes while there has been no record of Black-necked cranes in Northern Xinjiang. Note: The designations employed and the presentation of the material on this map do not imply the expression of any opinion whatsoever on the part of Research Square concerning the legal status of any country, territory, city or area or of its authorities, or concerning the delimitation of its frontiers or boundaries. This map has been provided by the authors. 